\title{
What can we learn from China's health system reform?
}

\author{
Qingyue Meng and colleagues assess what China's health system reform has achieved and \\ what needs to be done over the next decade
}

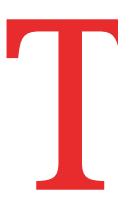

he Chinese central government started a first round of health system reform in 1996. The effectiveness of the reform was questioned after several years of implementation for a number of reasons. Firstly, complaints from the public about access to and affordability of healthcare increased. At that time, most people had no financial health protection and made high out-of-pocket payments for healthcare, which accounted for about $60 \%$ of total health expenditure. A large proportion of the population could not afford the healthcare they needed..$^{12}$ Secondly, the outbreak of severe acute respiratory syndrome in China in 2003 highlighted the importance of health for human development, and the government began to recognise the contribution of the health system to overall social and economic development. Thirdly, a leading state research institute published a report in 2005 which concluded that the 1996 health system reform had failed, which provoked more discussions about reform.

To respond to the concerns about the health system, the Chinese government began to plan another round of health system reform in 2007 and asked national and international organisations to provide reform proposals. Several ministries, coordinated by the National Development and Reform Commission and Ministry of Health, worked together to produce the

\section{KEY MESSAGES}

- China's round of health system reform in 2009 has made good progress

- Almost everyone is covered by the social health insurance system and basic public health service package, and unmet health needs and inequities have decreased

- Improvement in the quality of primary healthcare, further reform of public hospitals, better use of health resources, and integration of healthcare delivery and financing systems are still needed master policy document for the reform. In March 2009, the Central Committee of the Communist Party of China and the State Council issued the Opinions on Deepening Health System Reform. ${ }^{3}$ The aim of the reform was to establish an equitable and effective health system for all people (universal health coverage) by 2020 by strengthening healthcare delivery, health security, and provision of essential medicines.

China's health system reform is a large scale, long term social endeavour from which many lessons will be learnt. Analysis of the reform is important to help consider options for the future after this round of reform finishes in 2020. In this article we assess the achievements of the main reform policies, identify areas that need attention, and propose reform strategies for the next decade.

\section{Main reform policies}

China has a three tiered system for healthcare delivery: health organisations and providers operate at county, township, and village levels in rural areas, and at municipal, district, and community levels in urban areas. The public health sector is the main healthcare provider. In 2017 , $82 \%$ of inpatient care was provided by public hospitals. ${ }^{1}$ China has three main basic health insurance schemes-rural and urban resident based health insurance, which is funded mainly by government subsidies (about $70 \%$ of the total funds), and employee based health insurance funded by employer and employee contributions.

China's health system reform in the past decade covered five main areas: social health security, essential medicines, primary healthcare, basic public health service package, and public hospitals. The reform policies were designed to tackle access to healthcare and financial protection. Table 1 outlines the main reform policies, and their progress and challenges.

Financing reforms focused on expanding healthcare coverage and the benefit package of the social health insurance schemes for the population. Integration of the health insurance schemes for urban and rural residents is underway. Because of the large differences in per capita premiums and sources of funds, integration of the resident and employee based health insurance schemes is not planned.

Removing mark-up on drug prices as a source of financing for health providers is an important part of the policy reform on essential medicines. Reliance of hospitals on this price mark-up as a source of income had led to considerable overuse of drugs. Additional government subsidies and social health insurance funding have been the main way to compensate for the removal of mark-ups.

Strengthening the capacity of the primary healthcare system-mainly the rural village clinics, town health centres, and urban community health stations and centres-has been a priority of the reform. The government has made large investments and issued policies to attract and retain qualified health professionals in the primary healthcare system.

The purpose of the basic public health service package is to provide everyone with a defined healthcare package, regardless of income, residence, or other characteristics. The package is financed by a government per capita allocation mainly from the central government for low income provinces, and from local government (provincial and county) for high income provinces. The values of the fund and the package are adjusted every year.

Reforming public hospitals is important to tackle the problem of access to healthcare and financial protection because public hospitals account for more than $60 \%$ of total health expenditure. ${ }^{1}$ This reform is particularly difficult because of the need to balance the interests of the public hospitals, which are mostly responsible for their own finances, and the rest of society.

To implement the reforms, the State Council set up a State Council Health System Reform Office to coordinate the relevant ministries to develop specific reform policies-for example, hospital 
payment reform and remuneration policies for primary healthcare workers-and annual work plans to guide implementation of the reform activities by ministries and provincial governments. The office's annual evaluation of the performance of the ministries at the central level and the provincial governments influences promotion of leaders and allocation of government subsidies.

\section{Achievements}

Table 1 gives an overview of the main achievements and challenges of the reform in the five priority areas. Here, we highlight changes in government and social health expenditure and changes in unmet health needs and disparities in maternal and infant mortality as the health output and outcome.

\section{Increased public funding for health}

Financial contributions for health from government and through the social health security system have increased. Total health expenditure as a proportion of the gross domestic product changed little between 2000 and 2008 (4.57\% in 2000 and $4.55 \%$ in 2008), but increased from $5.03 \%$ in 2009 to $6.36 \%$ in $2017 . .^{1}$ Trends in total health expenditure from 2000 to 2017 show faster increases in health expenditure by the government and social health insurance system than from outof-pocket payments (fig 1). Between 2000 and 2005 , more than $50 \%$ of total health expenditure came from out-of-pocket payments; since then the proportion of health expenditure from out-of-pocket payments has declined and was $28 \%$ in $2017 .{ }^{1} \mathrm{Gov}$ ernment health expenditure increased by $¥ 10-20 \mathrm{bn}$ (£1.14-2.28bn; €1.29-2.59bn; $\$ 1.45-2.89 \mathrm{bn}$ ) every year between 2000 and 2006, and by $¥ 100-150 b n$ every year between 2009 and 2017. ${ }^{1}$ Health expenditure by the social health insurance system increased rapidly and accounted for $42 \%$ of total health expenditures in $2017 .{ }^{1}$ Social health insurance expenditure exceeded out-of-pocket payments in 2010; and gov-

\begin{tabular}{|c|c|c|c|}
\hline Reform priorities & Main reform policies & Progress & Challenges \\
\hline \multirow[t]{7}{*}{$\begin{array}{l}\text { Social health } \\
\text { security }\end{array}$} & $\begin{array}{l}\text { Expanding and sustaining population coverage of the } \\
\text { social health insurance system }\end{array}$ & $\begin{array}{l}95 \% \text { of the population covered by social health } \\
\text { insurance schemes by the end of } 2017^{14}\end{array}$ & \multirow{7}{*}{$\begin{array}{l}\text { Ineffective use of purchasing power } \\
\text { including use of the payment system } \\
\text { to control cost increases and improve } \\
\text { quality of care }\end{array}$} \\
\hline & $\begin{array}{l}\text { Extending the health service package of the social } \\
\text { health insurance system }\end{array}$ & $\begin{array}{l}\text { Per capita fund for resident based health insurance } \\
\text { increased from } ¥ 100^{\star} \text { in } 2008 \text { to } ¥ 700 \text { in } 2018 \text {, } \\
\text { about } 70 \% \text { from government subsides }\end{array}$ & \\
\hline & $\begin{array}{l}\text { Extending medical aid and social assistance } \\
\text { programmes for eligible poor people and those with } \\
\text { catastrophic medical expenditure }\end{array}$ & \multirow[t]{2}{*}{$\begin{array}{l}\text { Catastrophic illness insurance systems established in } \\
\text { all provinces }\end{array}$} & \\
\hline & Introducing a critical illness insurance scheme & & \\
\hline & & \multirow{3}{*}{$\begin{array}{l}\text { Integration of rural and urban basic health insurance } \\
\text { - systems underway }\end{array}$} & \\
\hline & $\begin{array}{l}\text { Integrating basic health insurance systems of rural } \\
\text { and urban residents }\end{array}$ & & \\
\hline & Reforming the payment system & & \\
\hline \multirow[t]{3}{*}{ Essential medicines } & $\begin{array}{l}\text { Removing price mark-ups of drugs as a source of } \\
\text { financing }\end{array}$ & See public hospital progress below & \multirow[t]{3}{*}{$\begin{array}{l}\text { Unfinished reform of the bulk procure- } \\
\text { ment system for drugs }\end{array}$} \\
\hline & $\begin{array}{l}\text { Formulating a national list of essential medicines and } \\
\text { reforming the drug procurement system }\end{array}$ & \multirow[t]{2}{*}{$\begin{array}{l}\text { Rates of antibiotic use in inpatient and outpatient care } \\
\text { decreased by } 50 \% \text { in selected tertiary hospitals }\end{array}$} & \\
\hline & Promoting rational use of antibiotics & & \\
\hline \multirow[t]{6}{*}{ Primary healthcare } & $\begin{array}{l}\text { Increasing investment in the primary healthcare } \\
\text { system }\end{array}$ & \multirow[t]{2}{*}{$¥ 965$ bn invested in primary healthcare ${ }^{1}$} & \multirow[t]{3}{*}{$\begin{array}{l}\text { Lack of effective incentives to attract } \\
\text { and retain primary healthcare workers }\end{array}$} \\
\hline & $\begin{array}{l}\text { Mobilising human resources for primary healthcare by } \\
\text { changing incentives }\end{array}$ & & \\
\hline & & \multirow{4}{*}{$\begin{array}{l}\text { Reliance of primary healthcare providers on } \\
\text { drug mark-ups reduced. Government budgets for } \\
\text { community and township health centres increased by } \\
\text { about } 20 \%{ }^{1}\end{array}$} & \\
\hline & $\begin{array}{l}\text { Expanding capacity for educating and training general } \\
\text { practitioners (more university places for family } \\
\text { medicine and more training programmes) }\end{array}$ & & $\begin{array}{l}\text { Difficulty in supporting a tiered } \\
\text { healthcare system }\end{array}$ \\
\hline & Removing drug mark-ups as a source of financing & & \\
\hline & Creating a contracting system for general practitioners & & \\
\hline \multirow[t]{3}{*}{$\begin{array}{l}\text { Basic public health } \\
\text { service package }\end{array}$} & $\begin{array}{l}\text { Providing basic public health service package to all } \\
\text { people through government subsidies }\end{array}$ & $\begin{array}{l}\text { Regular government budget support provided for the } \\
\text { package }\end{array}$ & \multirow[t]{3}{*}{$\begin{array}{l}\text { Low quality of public healthcare } \\
\text { provided in poor areas }\end{array}$} \\
\hline & & \multirow{2}{*}{$\begin{array}{l}\text { Per capita allocation for the package increased from } \\
¥ 15 \text { in } 2009 \text { to } ¥ 55 \text { in } 2017^{67}\end{array}$} & \\
\hline & $\begin{array}{l}\text { Supporting programmes to control the main public } \\
\text { health problems }\end{array}$ & & \\
\hline \multirow[t]{8}{*}{ Public hospitals } & Replacing fee for service by an alternative payment & \multirow{3}{*}{$\begin{array}{l}\text { Share of drug income of total hospital income reduced } \\
\text { from } 42 \% \text { in } 2008 \text { to } 30 \% \text { in } 2018 \text {. Reliance on price } \\
\text { - mark-ups on drugs reduced. Government budgets for } \\
\text { public hospitals increased by } 1.5 \%^{1}\end{array}$} & Escalating costs of medical care \\
\hline & system & & \multirow{7}{*}{$\begin{array}{l}\text { Overuse of healthcare and technolo- } \\
\text { gies }\end{array}$} \\
\hline & Improving pricing policies and removing mark-up of & & \\
\hline & & \multirow{2}{*}{$\begin{array}{l}\text { Clinical pathways for } 442 \text { diseases were developed by } \\
\text { the end of } 2015 \text { and } 65 \% \text { of secondary and tertiary } \\
\text { hospitals implemented case based payment reform by } \\
\text { the end of } 2017^{89}\end{array}$} & \\
\hline & $\begin{array}{l}\text { Encouraging the creation of consortia or alliances of } \\
\text { healthcare providers }\end{array}$ & & \\
\hline & & \multirow{3}{*}{$\begin{array}{l}\text { Tiered healthcare system started by } 95 \% \text { of } \\
\text { municipalities by the end of } 2017^{10}\end{array}$} & \\
\hline & $\begin{array}{l}\text { Establishing a tiered service delivery system (tertiary, } \\
\text { secondary, and primary healthcare providers with } \\
\text { clearly defined functions) }\end{array}$ & & \\
\hline & $\begin{array}{l}\text { Encouraging the use of clinical pathways and } \\
\text { guidelines }\end{array}$ & & \\
\hline
\end{tabular}




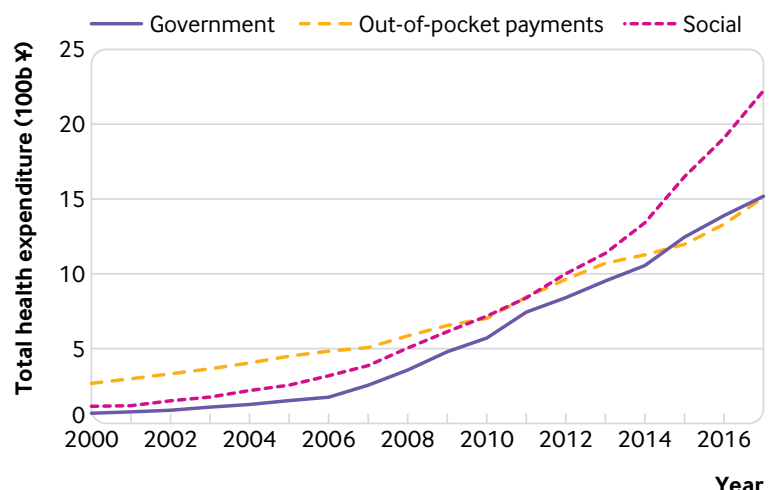

Fig 1 | Total health expenditure by source, $2000-17^{1}(1 ¥=£ 0.11 ; € 0.13 ; \$ 0.14)$

ernment health expenditure exceeded outof-pocket payments in 2015.

Low income provinces and counties have received additional government health subsidies. In low income counties, $80 \%$ of the funds for the rural health insurance scheme came from government subsidies, half from the central and half from provincial governments, and 100\% of the funds for the basic public health programmes came from higher level governments. ${ }^{111}$ During the reform period, social health insurance schemes and the basic public health service package were extended to cover everyone. ${ }^{11}$ Providing universal coverage by expanding social health insurance schemes and public health programmes was possible mainly because of additional and continuing financial support from the government.

Improved access to healthcare and decreased health inequality

Before the introduction of the social health insurance schemes, a large proportion of the population did not access healthcare even when needed, mainly because of financial barriers. Between 2003 and 2008, the proportion of patients who were advised by doctors that they needed treatment in hospital but did not use inpatient care decreased by $4.5 \%$ (from $29.6 \%$ to $25.1 \%) .{ }^{12}$ The proportion decreased by $8.0 \%$ between 2008 and 2013 (fig 2). ${ }^{12}$ The proportion of patients who needed hospital care but could not afford it declined from $17.6 \%$ in 2008 to $7.4 \%$ in $2013 .^{12}$ Changes in proportions of unmet needs for outpatient care were similar to inpatient care. Extended coverage of the population through social health insurance schemes and increased availability of healthcare are the main reasons for the greater accessibility to healthcare. ${ }^{13}$

An important reform target was reduction in health disparities and the country has made substantial health improvements. For example, differences in the maternal mortality rate between low, middle, and high income provinces (categorised by per capita gross domestic product) decreased from 2005 to 2017 (fig 3). Differences in maternal mortality rates between urban and rural areas also decreased, from 28/100 000 live births between 2000 and 2008 on average to 2.3/100 000 live births between 2009 and 2017 on average. ${ }^{1}$ Differences in the infant mortality rate between rural and urban areas also narrowed. In 2000, the difference in the infant mortality rate between rural and urban areas was 25.2\% (37\% in rural areas and $11.8 \%$ in urban); by 2017 , the difference was only $3.8 \%$ (7.9\% in rural areas and 4.1\% in urban). ${ }^{1}$ Support by social health insurance schemes for childbirth in a health facility which targeted low income areas helped improve maternal and child health outcomes in poorer areas and reduce health disparities. ${ }^{14}$

\section{Challenges}

The health system in China is more complex than that of many other countries because of the country's large population and regional diversity. China has made good progress in its health system reform but challenges remain.

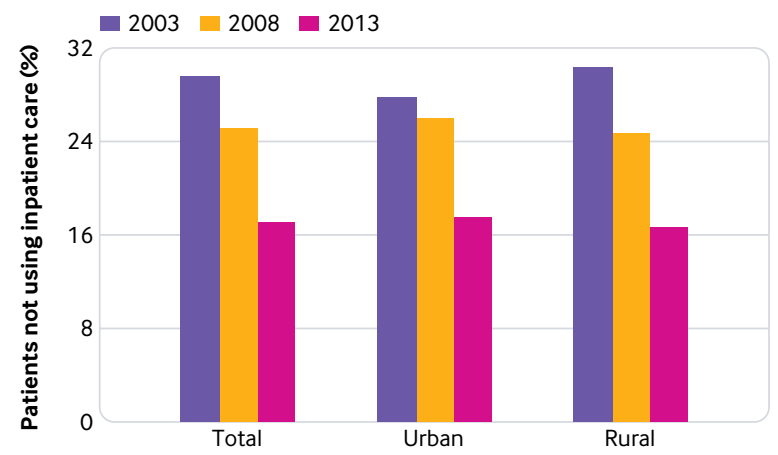

Fig 2 | Percentage of patients who did not use inpatient care when needed ${ }^{12}$

\section{Low use and capacity of primary healthcare providers}

The low use and capacity of primary healthcare providers has two main reasons. Firstly, the quality of care given by primary healthcare providers is inadequate. From 2005 to 2015, the proportion of healthcare services provided by primary care decreased by $7 \% .{ }^{15}$ In $2010,5.6 \%$ of the doctors in township health centres had a formal medical education (five years of medical school), ${ }^{16}$ which increased to only $10 \%$ in $2017 .{ }^{1}$ Incentives to attract and retain more qualified health professionals in the primary care system are essential to improve quality of care. ${ }^{17}$ Secondly, the fee-for-service payment system in hospitals gives hospitals an incentive to try to attract and retain patients who could otherwise use primary healthcare providers.

Increased cost of medical care and inefficient use of resources

Medical costs have increased more rapidly since 2009. In general hospitals, medical expenditure per patient discharged increased by $17.2 \%$ between 2005 and 2008, and by $22.1 \%$ between 2010 and 2013. ${ }^{116}$ Changes in costs for outpatient care were similar. In general hospitals, medical expenditure per outpatient visit increased by $15.5 \%$ between 2005 and 2008 and $21.7 \%$ between 2010 and $2013 .{ }^{1}$ The proportion of out-of-pocket payments for healthcare decreased, but the financial burden of using healthcare did not fall much, especially for poor households. ${ }^{18}$ The share of drug costs in total hospital expenditure has fallen, but overall hospital expenditure is still increasing. ${ }^{19}$

When health insurance coverage is universal, a moral hazard situation ariseshealthcare providers may overprovide and healthcare users overuse health services. This situation and the fee for service payment system are argued to be the main factors driving overprovision of healthcare in China and the resulting waste of health 


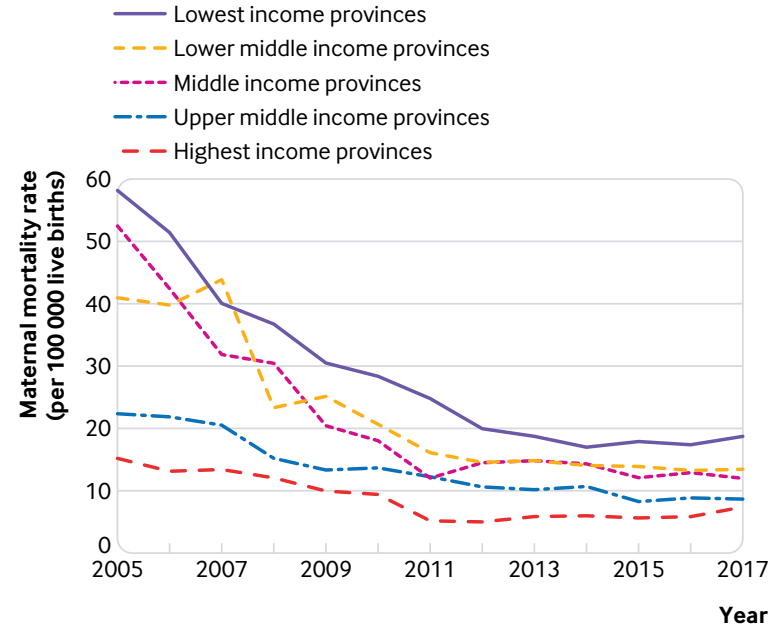

Fig 3 | Maternal mortality rate by income level of provinces, $2005-17^{1}$

resources. ${ }^{20}$ Fig 4 shows China's ranking in the world for per capita health expenditure (health input), under $5 \mathrm{~s}$ mortality rate, and life expectancy at birth (health outcomes). China ranks lower on per capita health expenditure (that is, it spends relatively less) than on the other two indicators, so the country has better health outcomes at lower cost; in other words it is relatively efficient. However, the differences in the rankings are decreasing, indicating that China's relative efficiency in using health resources is decreasing.

Allocation of government subsidies is mainly based on service volume and activities rather than health outcomes. In addition, health resources are skewed to the hospital sector rather than primary and preventive care, although these two services are important determinants of efficiency. In 2016, the rate of hospital admission in China was $16.4 \%$, higher than the average for countries of the Organisation for Economic Cooperation and Development, services. ${ }^{122}$ erly established. which implies that China needs to examine the appropriateness of inpatient care, including overuse and misuse of healthcare

\section{Insufficient coordination and fragmented systems}

To improve population health and achieve "health in all policies," coordination and cooperation between related sectors are important. More effective mechanisms are needed to improve intersectoral coordination for health. Delivery of health services should be people centred, integrated, and cost effective, and ensure continuity of care. However, many of the health institutions lack motivation to cooperate with others. Even though medical consortiums and alliances are encouraged by the government and have been piloted in many places, mechanisms to coordinate health institutions to provide continuing care have not been prop-

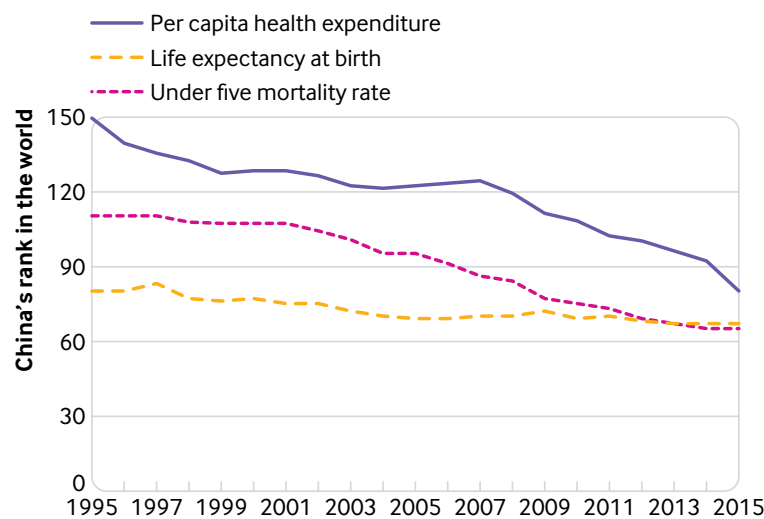

Year

Fig 4 | China's world ranking for per capita health expenditure, mortality among children 5 years, and life expectancy at birth, 1995-15 21
The financing system is fragmented with separate financing for different health programmes and population groups. ${ }^{23}$ The reform has tried to allow health insurance to be portable for all people, but most rural migrants in cities still need to go back to their home town to access insurance benefits.

\section{Areas for further reform Integrated health system based on primary care}

Coordination between different sectors should be strengthened to make health in all policies workable and achievable. The current reform has shown that success requires effective collaboration between related sectors led by a strong coordinating authority. The existing hospital centred healthcare system should be transformed to a system based on primary care, where health providers are closely connected and coordinated to offer continuing and integrated care. Both organisational and functional structures of healthcare institutions should be changed. People should be able to receive good quality and convenient healthcare from nearby health providers. Integration of health services and a three tiered structure of primary, secondary, and tertiary providers should be developed with primary care as the foundation. A collaborative relationship between primary healthcare and hospital sectors is essential. A competent health workforce is also important; government efforts should continue to focus on incentives (financial rewards and professional development opportunities) to attract and retain qualified health professionals in the primary healthcare system.

\section{Consolidated health financing system}

Strategies to achieve universal health coverage can provide direction for integrating financing sources for both curative and preventive care. The current separate financing mechanisms, where health insurance schemes cover curative care only and the basic public health service package covers preventive care only, can be combined to encourage hospitals and clinics to offer more preventive care services. When integrating the rural and urban health insurance schemes, policies should be developed to ensure protection of poor and rural people. Reform of the payment system should be accelerated and cost containment and quality improved. Incentives should be adapted to strengthen the primary healthcare system. 


\section{Monitoring and evaluation system}

The government should recognise the importance of establishing an effective performance evaluation system for implementation of a Healthy China strategy. Quality of care and health outcomes need to have sufficient weight in the evaluation system. The main health indicators should be included in the social and economic development agenda and in the performance evaluation of government at central and local levels. A health impact assessment system should be developed to generate more resources and effort from all related sectors to achieve better population health.

\section{Conclusion}

China has implemented a comprehensive health system reform over the past decade which focused on strengthening the capacity of primary care, extending and improving social health insurance coverage, providing basic public health services to everyone, reforming public hospitals, and improving medicines policies.

Both central and local governments have mobilised substantial political and financial resources to implement the reform. Almost everyone has been covered by the social health insurance system and basic public health service package. Mark-up of drug prices has been stopped in public hospitals and primary healthcare providers. Unmet health needs and inequities in some health indicators have decreased.

Some challenges remain. The quality of care in primary healthcare has not improved greatly, mostly because of the inadequate training of the healthcare providers. The cost of medical care is still increasing as a result of incomplete reform of public hospitals including ineffective utilisation of the payment system. Inefficient use of health resources is prevalent mainly because of overuse of healthcare and uneven distribution of health resources. Healthcare delivery and financing systems are fragmented because of constraints in the governance structure.

Building a well coordinated and integrated health system based on primary care and an evaluation system based on health outcomes is needed to further develop the health system in China.
We thank Mr Li Qi from Peking University China Center for Health Development Studies for his help in the data work.

Contributors and sources: QM's research interests include health financing and health system evaluation. AM's research focuses on health economics and policy. LW focuses on policy development for controlling non-communicable diseases. $\mathrm{OH}$ has expertise in social and health development. All authors contributed to the design and preparation of the article. QM is the guarantor.

Competing interests: We have read and understood BMJ policy on declaration of interests and have no relevant interests to declare.

Provenance and peer review: Commissioned; externally peer reviewed.

This article is part of a series proposed by Peking University China Center for Health Development Studies and commissioned by The BMJ. The BMJ retained full editorial control over external peer review, editing, and publication of these articles. Open access fees are funded by Peking University Health Science Center.

Qingyue Meng, professor $^{1}$

Anne Mills, professor ${ }^{2}$

Longde Wang, professor ${ }^{3}$

Qide Han, Professor ${ }^{4}$

${ }^{1}$ China Center for Health Development Studies, Peking University, Beijing, China

${ }^{2}$ London School of Hygiene and Tropical Medicine, London, UK

${ }^{3}$ China Association of Preventive Medicine, Beijing, China

${ }^{4}$ Health Science Centre, Peking University, Beijing, China

Correspondence to: Q Meng

qmeng@bjmu.edu.cn

\section{(c) (1) (8) OPEN ACCESS}

This is an Open Access article distributed in accordance with the Creative Commons Attribution Non Commercial (CC BY-NC 4.0) license, which permits others to distribute, remix, adapt, build upon this work non-commercially, and license their derivative works on different terms, provided the original work is properly cited and the use is non-commercial. See: http://creativecommons.org/ licenses/by-nc/4.0/.

\section{Check for updates}

1 National Health Commission. China's health statistics yearbook 2018. Peking Union Medical College Press, 2018.

2 Center for Health Statistics and Information, National Health and Family Planning Commission. An analysis report of national health services survey 2008. Peking Union Medical College Press, 2009.

3 Central Committee of the Communist Party of China, State Council. Opinions on deepening health system reform. Zhongfa 2009 No. 6. 2009. http://www.china.org.cn/government/scio-pressconferences/2009-04/09/content 17575378.htm

4 National Bureau of Statistics. China statistical yearbook 2018. National Statistical Press, 2018.
5 He P, Sun Q, Shi L, Meng Q. Rational use of antibiotics under the context of China's health system reform. BMJ 2019;365:l4016. doi:10.1136/bmj.l4016

6 Yang L, Sun L, Wen L, et al. Financing strategies to improve essential public health equalization and its effects in China. Int J Equity Health 2016;15:194. doi:10.1186/s12939-016-0482-x

7 Qin J. Progress in basic public health service projects in China. Chin J Public Health 2017;33:1289-97.

8 National Health and Family Planning Committee. Responses to No 7482 suggestion from the Fifth Session of the Twelfth National People's Congress. 7 July, 2017. http:// www.nhc.gov.cn/wjw/jiany/201801/ f1b01625241f4c9ba3b9f57eb9796f66.shtml

9 China Government Network. Progress report of public hospital reform and building of medical consortia to the State Council Member meeting, 2017. http://www.gov.cn/xinwen/2017-10/09/ content $5230395 \mathrm{htm}$

10 Department of Hospital Management, National Health Commission. Work priorities to implement tiered health care system. 2018 http://www.nhc.gov. cn/yzygj/s3594r/201808/1fc30369e06e43ef820 39cd7d490d0d1.shtml

11 Yuan B, Balabanova D, Gao J, Tang S, Guo Y. Strengthenng public health services to achieve universal health coverage in China. BMJ 2019;365:12358. doi:10.1136/bmj.l2358

12 Center for Health Statistics and Information, National Health and Family Planning Commission. An analysis report of national health services survey 2013. Peking Union Medical College Press, 2015.

13 Meng Q, Xu L, Zhang Y, et al. Trends in access to health services and financial protection in China between 2003 and 2011: a cross-sectional study. Lancet 2012;379:805-14. doi:10.1016/S01406736(12)60278-5

14 Zi L, Li H, Yin K. Impact of NCMS and subsidies on maternal and child health care. Chinese J Women Child Health 2015;6:66-8.

15 Zhang L, Cheng G, Song S, et al. Efficiency performance of China's health care delivery system. Int J Health Plann Manage 2017;32:254-63. doi:10.1002/hpm.2425

16 Ministry of Health. Chinese health statistical yearbook 2011. Peking Union Medical College Press, 2012.

17 Ma X, Wang H, Yang L, Shi L, Liu X. Incentivising China's primary health care providers. BM/ 2019:365:12406 doi:10.1136/bmj.12406

18 Fang $\mathrm{H}$, Eggleston K, Hanson K, Wu M. Enhancing financial protection under China's social health insurance to achieve universal health coverage. BMJ 2019;365:l2378. doi:10.1136/bmj.l2378

19 Xu J, Jian W, Zhu K, Kwon S, Fang H. Reforming public hospital financing in China: progress and challenges BMJ 2019;365:14015. doi:10.1136/bmj.l4015

20 Liu H. Does over treatment exist in China? Study on the efficiency of hospital care across provincial hospitals. Soc Sci (Kans) 2015;12:65-75.

21 World development indicators. World Bank, 2018. https://datacatalog.worldbank.org/dataset/worlddevelopment-indicators

22 OECD. Health statistics 2018-frequently requested data. http://www.oecd.org/health/health-systems/.

23 Meng Q, Fang H, Liu X, Yuan B, Xu J. Consolidating the social health insurance schemes in China: towards an equitable and efficient health system. Lancet 2015;386:1484-92. doi:10.1016/S01406736(15)00342-6

Cite this as: BMJ 2019;365:12349

http://dx.doi.org/10.1136/bmj.l2349 